\title{
Preparation of silica hydrogels using a synthetic peptide for application as carriers for controlled drug release and mesoporous oxides
}

\author{
Yuki KAWACHI, ${ }^{* * *}$ Shin-ichi KUGIMIYA* and Katsuya KATO**,† \\ ${ }^{*}$ Materials Chemistry Course, Graduate School of Engineering, Aichi Institute of Technology, \\ 1247 Yachigusa Yakusa-cho, Toyota, Aichi 470-0392, Japan \\ **National Institute of Advanced Industrial Science and Technology (AIST), \\ 2266-98 Anagahora, Shimosidami, Moriyama-ku, Nagoya 463-8510, Japan
}

\begin{abstract}
Sol-gel methods is a commonly used methods for encapsulation of enzyme and drug, but this method has two disadvantages of using acid or base as a catalyst and being difficult to control pore size of silica material. Even though synthesis under mild condition or silica with controlled pore size in the mesopore region have been reported, it is still difficult to achieve these two characteristics simultaneously. In this work, we chose 10 -mer peptides of lysine $(\mathrm{K})$, histidine $(\mathrm{H})$, and block and alternate $\mathrm{K}$ and aspartic acid (D) as catalysts for silica mineralization, and silica gels were prepared using the synthetic peptides and a "leave to stand" synthesis method. The resulting silica hydrogels were lyophilized, and their surface areas and morphologies were characterized using the Brunauer-Emmett-Teller (BET) method and field-emission scanning electron microscopy (FE-SEM), respectively. Silica gels prepared by the "leave to stand" method with $\mathrm{K}_{10}$ and $\mathrm{H}_{10}$ exhibited a mesoporous structure with high surface area (576 and $451 \mathrm{~m}^{2} \mathrm{~g}^{-1}$, respectively) and pore volume $\left(0.35\right.$ and $0.30 \mathrm{~cm}^{3} \mathrm{~g}^{-1}$, respectively). SEM images confirmed the mesoporous structure of these gels. We encapsulated fluorescein sodium salt as a model drug within silica hydrogels using $K_{10}$ and $\mathrm{H}_{10}$ as a catalyst. The silica hydrogel prepared using $\mathrm{H}_{10}$ exhibited faster release of the drug (approximately 2.5 -fold) than gels prepared using $K_{10}$. These results demonstrate that by changing isoelectric point binding between the peptide and pore structure, the synthesized silica hydrogel-peptide composites can be designed to control the release rate of an encapsulated drug.

(2014 The Ceramic Society of Japan. All rights reserved.
\end{abstract}

Key-words : Silica gel, Peptide, Biomineralization, Encapsulation, Drug delivery systems, Mesoporous

[Received October 10, 2013; Accepted December 3, 2013]

\section{Introduction}

Silica gel prepared by the sol-gel process using an acid or base as a catalyst at room temperature is a glass-like ceramic material. ${ }^{1), 2)}$ This gel has found applications across many fields, such as optics, electronics, nanotechnology, medicine, biology, chemistry, materials science, and separation science. At the interface of biology, chemistry, and materials science, the immobilization of biomolecules via encapsulation within a sol-gel-derived matrix has been studied in recent years. ${ }^{3)-6)}$ Encapsulation restricts the mobility of the biomolecules contained within a confined space and can prevent denaturation even in harsh environmental conditions related to temperature, $\mathrm{pH}$, and solvents. For instance, creatine kinase encapsulated within silica gel retains $50 \%$ of its activity around 10 times longer at $47^{\circ} \mathrm{C}(125 \mathrm{~h})$ than the free enzyme $(13 \mathrm{~h})$ at the same temperature. ${ }^{7)}$ Alkaline phosphatase naturally exhibits its optimum activity at $\mathrm{pH} 9.5$ but appears to remain active at a $\mathrm{pH}$ as low as 0.9 when encapsulated within silica gel. ${ }^{8)}$ For this reason, many biomolecules have been trapped within sol-gel silica, and this research has led to some of the most interesting and important applications of these materials, paving the way for their use in the design and fabrication of biosensing devices for the rapid detection of analytes in a variety of matrixes. ${ }^{6), 9)-11)}$ Whereas encapsulation using the solgel method has advantages, it can also decrease the activity of

Corresponding author: K. Kato; E-mail: katsuya-kato@aist. go.jp encapsulated drugs and proteins (enzymes), because preparation of silica gel by this method requires the use of an acid or base as a catalyst. Thus, to avoid any reduction in the activity of the encapsulated biomolecule, a method for synthesizing silica gel under mild conditions, such as neutral $\mathrm{pH}$ and ambient temperate, is needed. Also, the pore size of the gel carrier must be carefully considered relative to the size of the encapsulated biomolecule. The pore sizes of silica gels are relatively small $(<2 \mathrm{~nm})$, which is a drawback for many applications due to the limited diffusion of the substrate and water. When the pore sizes are much larger than that of an encapsulated enzyme, the enzyme will freely leach from inside the host. Many enzymes (e.g., lipase and glucose oxidase) are $2-10 \mathrm{~nm}$ in size. Therefore, it is desirable that silica gel has a suitable pore size near this range. Mesoporous silica has been established as one of the most effective solid carriers of immobilized enzymes because of its large specific surface area and uniform pore size. ${ }^{12)}$ However, the immobilized enzymes are leached during the washing and reaction processes due to the weak electrostatic interactions between the enzymes and the mesoporous silica surface.

Biomineralization is a natural process in humans and animals that leads to the formation of biomineral-based structures such as bones, shells, and teeth. ${ }^{13)-16)}$ In general, biomineralization occurs in aqueous solution at neutral $\mathrm{pH}$, room temperature, and normal pressure. In addition, biomineral-based structures have good mechanical properties. Thus, biomineralization not only is a lowenergy process and an environmentally friendly process but it also has potential for the creation of novel functional inorganic 

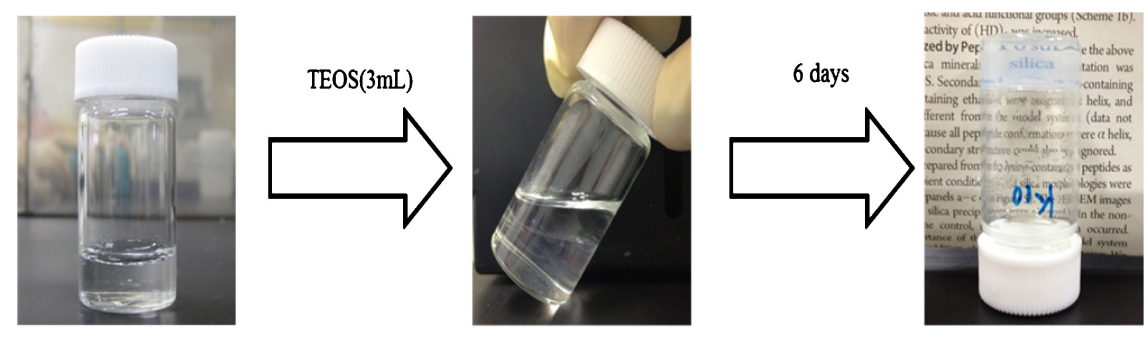

peptide (1.5mg)

in $\mathrm{H}_{2} \mathrm{O}(3 \mathrm{~mL})$

Fig. 1. Silica gel preparation using synthetic peptide and the "leave to stand" method.

materials. ${ }^{17-22)}$ In the case of silica, the reaction is called biosilicification, and this process has been actively studied, particularly in diatoms and marine sponges. ${ }^{21), 23), 24)}$ Additionally, many researchers have been working to characterize silica formation from biological and bioinspired catalysts, such as R5 peptide, lysozyme, and poly-L-lysine. ${ }^{23), 25)-34)}$

To the best of our knowledge, only a few studies have examined the control of pore size of inorganic oxides using a bioinspired catalyst. ${ }^{35)-38)}$ These studies have demonstrated the feasibility of using the secondary structure of a polypeptide to manipulate the pore size of oxides. However, to maintain the secondary structure of the peptides, these methods require harsh conditions to synthesize silica with a controlled pore size, and thus, they are not suitable for creating silica while simultaneously encapsulating enzymes or drugs.

The present study demonstrates a novel method for synthesizing silica gel with a controlled mesoporous structure using peptide-catalyzed reactions under milder conditions. In a previous study, we investigated the effect of a peptide sequence with two functional groups. ${ }^{21)}$ In that study, we selected lysine (K) and histidine $(\mathrm{H})$ as the standard amino acids in our peptide sequence, because the side chains of $\mathrm{K}$ and $\mathrm{H}$ have a high catalytic ability for silica mineralization. Additionally, aspartic acid (D), which does not have catalytic activity for silica mineralization, was incorporated into the peptide sequence. We confirmed the charge relay effect, verifying the activity of the enzyme's basic functional groups (amino and imidazole groups) and the carboxyl group of aspartic acid. In addition, we elucidated the effect of the functional group combination and demonstrated that the peptide sequence design enables the control of nano-scale silica particle size. In our previous study, we carried out the sol-gel reaction in the process of adding TEOS to in $90 \mathrm{vol} \%$ ethanol containing peptide. However, this method is not suitable for encapsulating an unstable substance because a large amount of ethanol was contained. Therefore, the reaction was conducted without ethanol in the present study. When the reaction takes place in ethanol, the primary silica particles are considered dispersed and their spherical diameter is expanded accordingly. However, when the reaction takes place in water, the primary particles may be aggregated, and thereby their spherical diameter will not grow. Thus, the present study investigated a "leave to stand" reaction process to slow the reaction rate and allow the particles to be dispersed, expecting the pore size to increase with increasing particle diameter. We attempted to prepare silica gel with a pore size of $2-10 \mathrm{~nm}$ without the use of an acid or a base and an organic template, and we encapsulated an unstable substance within the resultant sol-gel silica matrix.

\section{Experimental procedure}

\subsection{Materials}

TEOS was purchased from Shin-Etsu Chemical Co. (Tokyo, Japan). CLEAR amide resin and 9-fluorenylmethyloxycarbonyl (Fmoc) amino acids were purchased from the Peptide Institute (Osaka, Japan). 1,3-Diisopropylcarbodiimide was purchased from the Sigma-Aldrich Co. (St. Louis, MO). 1-Hydroxy-7-azabenzotriazole was from Watanabe Chemical Industries (Hiroshima, Japan). Dichloromethane (DCM), N, N-dimethylformamide (DMF), piperidine, pyridine, trifluoroacetic acid, thioanisole, ethylenedithiol, and diethylether were purchased from Wako Pure Chemical Industries (Osaka, Japan). Acetic anhydride was from Kanto Chemical Co. (Tokyo, Japan). Fluorescein sodium salt (FSS, Sigma-Aldrich Co.) was used as a model drug.

\subsection{Peptide synthesis}

Four different 10-mer peptides, $\mathrm{K}_{10}, \mathrm{H}_{10}, \mathrm{~K}_{5} \mathrm{D}_{5}$, and $(\mathrm{KD})_{5}$, were synthesized by combinatorial solid-phase peptide synthesis as described previously, ${ }^{21)}$ and their structures were confirmed by matrix-assisted laser desorption ionization time-of-flight mass spectrometry (MALDI-TOF-MS) with $\alpha$-cyano-4-hydroxycinnamic acid as a matrix.

To investigate the secondary structures of the peptides, the circular dichroism (CD) spectrum was measured on a JASCO J-820K spectropolarimeter (Jasco Inc., Tokyo, Japan). The CD spectra were recorded at room temperature in the region of 190$260 \mathrm{~nm}$, with an integration number of 16 .

\subsection{Synthesis of silica hydrogel}

Silica hydrogel was synthesized using two methods: the "leave to stand" sol-gel method and general mixing. For the "leave to stand" method (Fig. 1), $1.5 \mathrm{mg}$ of synthetic peptide was dissolved in $3 \mathrm{~mL}$ ultrapure water. Then TEOS was slowly added to the upper layer of this solution, and subsequent hydrolysis occurred from the interface between TEOS and water. This mixture was left to stand at $20^{\circ} \mathrm{C}$ for 6 days for gelation to occur. Silica gel prepared by "mixing" achieved gelation within 3 days. The resultant gels were washed with ultrapure water, frozen at $-30^{\circ} \mathrm{C}$ for 1 day, and then freeze dried.

\subsection{Characterization}

Particle morphology was observed using field-emission scanning electron microscopy (FE-SEM; S-4300, Hitachi Co., Tokyo, Japan) with an accelerating voltage of $10.0 \mathrm{kV}$. Before visualization, the samples were sputter coated with platinum using the Hitachi E-1020 ion sputter (Hitachi High-Technologies, Tokyo, 
(a)

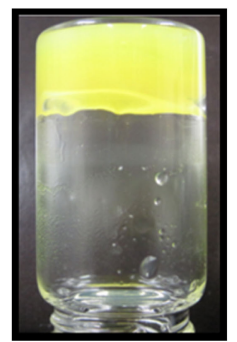

(b)<smiles>COc1ccc2c(-c3ccccc3C(=O)[O-])c3ccc(=O)cc-3oc2c1</smiles>

Scheme 1. (a) Silica hydrogel encapsulating FSS, and (b) structure of FSS.

Japan). The surface area and pore diameter were measured using nitrogen $\left(\mathrm{N}_{2}\right)$ adsorption/desorption measurements in a TriStar 3000 system (Shimadzu Co., Kyoto, Japan). Pore diameter distributions were calculated from desorption branches by the Barrett-Joyner-Halenda (BJH) method. Specific surface areas were calculated by the Brunauer-Emmett-Teller (BET) method based on desorption isotherms. Transmission electron microscopy (TEM) images were taken using the JEOL JEM-2010 electron microscope (JEOL, Tokyo, Japan) operated at $200 \mathrm{kV}$. Fourier transform infrared (FT-IR) absorption spectra were recorded using a JASCO MFT-2000 FT-IR spectrophotometer (Jasco Inc., Tokyo, Japan); spectral range of $4000-500 \mathrm{~cm}^{-1}, 50$ scans. The samples were measured using a $\mathrm{KBr}$ disk. Thermogravimetric-differential thermal analysis (TG-DTA) curves were collected using a SSC/ 5200 apparatus (Seiko Instruments, Tokyo, Japan). The samples were heated from room temperature to $1050^{\circ} \mathrm{C}$ at a rate of $10^{\circ} \mathrm{C}$ $\mathrm{min}^{-1} .{ }^{29} \mathrm{Si}$ MAS NMR spectra were recorded at $59.587 \mathrm{MHz}$ on Varian Unity INOVA 300 spectrometer (Darmstadt, Germany) with a $5 \mathrm{~mm}$ probe. The solid-state ${ }^{29} \mathrm{Si}$ NMR spectra were measured on Varian Unity INOVA-300 spectrometer operated at 59.59 $\mathrm{MHz}$ for the ${ }^{29} \mathrm{Si}$ nuclei with an $80 \mathrm{~ms}$ acquisition period with $63 \mathrm{kHz}$ of $1 \mathrm{H}$ decoupling radio frequency as a continuous wave. The DD/MAS (dipolar decoupling and magic-angle spinning) method was used with $3.3 \mu$ s single pulse of the $\pi / 2$ pulse for the ${ }^{29} \mathrm{Si}$ nuclei in zirconium rotors of $7 \mathrm{~mm}$ in diameter and spun at the magic angle at $5 \mathrm{kHz}$. The recycle time between the $\pi / 2$ pulses was $100 \mathrm{~s}$ in DD/MAS. All fluorescence measurements were carried out on a RF5300 PC spectrofluorophotometer (SHIMADZU, Kyoto, Japan) equipped with a $150 \mathrm{~W}$ xenon lamp using $1.00 \mathrm{~cm}$ quartz cells.

\subsection{Release studies of fluorescein sodium salt}

Silica gel samples were prepared with $1 \mathrm{mg}$ of the model drug, fluorescein sodium salt (FSS), together with synthetic peptide $\left(\mathrm{K}_{10}\right.$ and $\left.\mathrm{H}_{10}\right)$ dissolved in $3 \mathrm{~mL}$ ultrapure water, and all other steps of the synthesis protocol followed the conditions used for the previous "leave to stand" preparations (Scheme 1). The release experiments were carried out by placing the FSS-containing silica hydrogel in $10 \mathrm{mM}$ phosphate buffer solution of $\mathrm{pH} 7.0$ at ambient temperature under a constant stirring rate. The concentration of fluorescein in the buffer solution was measured with a fluoroscope spectrophotometer in phosphate buffer at excitation maximum of $494 \mathrm{~nm}$ and emission maximum of $517 \mathrm{~nm}$.

\section{Results and discussion}

\subsection{Confirmation of peptide synthesis}

The CD and MALDI-TOF-MS results for the peptides used in this study are described in our previous paper. ${ }^{20)}$ The CD spectra of the synthesized peptides at $\mathrm{pH} 7$ show a negative maximum peak at $197 \mathrm{~nm}$, and the secondary structures of the peptides
Table 1. Water content of silica hydrogels prepared from synthetic peptides

\begin{tabular}{cccc}
\hline $\begin{array}{c}\text { Synthetic } \\
\text { peptide }\end{array}$ & $\begin{array}{c}\text { (1): Silica hydrogel } \\
\text { weight }(\mathrm{g})\end{array}$ & $\begin{array}{c}(2) \text { : Weight of } \\
\text { silica framework }(\mathrm{g})\end{array}$ & $\begin{array}{c}(2) /(1) \\
(\%)\end{array}$ \\
\hline $\mathrm{K}_{10}{ }^{\mathrm{a}}$ & 3.07 & 0.21 & 6.84 \\
$\mathrm{H}_{10}{ }^{\mathrm{a}}$ & 3.27 & 0.15 & 4.58 \\
$\mathrm{~K}_{5} \mathrm{D}_{5}{ }^{\mathrm{a}}$ & 3.12 & 0.25 & 8.01 \\
$(\mathrm{KD})_{5}{ }^{\mathrm{a}}$ & 3.06 & 0.19 & 6.21 \\
$\mathrm{~K}_{10}{ }^{\mathrm{b}}$ & 6.00 & 0.98 & 16.3 \\
\hline
\end{tabular}

a: leave to stand, b: mixing.

were assigned a random coil configuration. The influence of the other secondary structures such as the $\alpha$-helix and $\beta$-sheet was almost negligible. In addition, peptide synthesis was confirmed by MALDI-TOF-MS with $\alpha$-cyano-4-hydroxycinnamic acid used as the matrix. The calculated molecular weights of the peptides used in this study were in agreement with their measured maximum peak values.

\subsection{The effects of synthesis conditions on silica content of prepared hydrogels}

Table 1 lists the weights of the generated silica hydrogels and the corresponding silica content. It was confirmed that all silica hydrogels prepared by the "leave to stand" method contained less than $10 \%$ silica $\left[\mathrm{K}_{10}, 6.9 \% ; \mathrm{H}_{10}, 4.6 \% ; \mathrm{K}_{5} \mathrm{D}_{5}, 8.0 \%\right.$; and $(\mathrm{KD})_{5}$ : $6.2 \%$ ]. On the other hand, gel prepared by mixing was $16.3 \%$ silica. The silica content of gels prepared by the "leave to stand" method was less than that of gel prepared by mixing, indicating that the amount of produced ethanol was lower. Therefore, the "leave to stand" method will have fewer negative effects on relatively unstable drugs and enzymes during encapsulation.

\subsection{The effects of synthesis conditions on silica particle structure}

To confirm that the different reaction conditions and catalysts influenced silica particle diameter, the prepared silica hydrogels were lyophilized, and the morphology of silica particles in the resultant powders was observed using FE-SEM. The sphere diameter of silica particles prepared by mixing was less than $10 \mathrm{~nm}$ [Fig. 2(a)]. Additionally, FE-SEM images confirmed that silica spheres were tightly packed together. By contrast, the silica spheres prepared by the "leave to stand" method had a diameter of approximately $30 \mathrm{~nm}$ and were uniform in size [Fig. 2(b)]. These results indicate that with the "leave to stand" method, the silica sphere diameter is expanded due to the slower reaction rate. The differences in particle diameter with different catalysts are shown in Figs. 2(b)-2(e). The diameter of silica spheres prepared using $\mathrm{H}_{10}$ was approximately $30 \mathrm{~nm}$, similar to that with $\mathrm{K}_{10}$. However, the corresponding diameters for $(\mathrm{KD})_{5}$ and $\mathrm{K}_{5} \mathrm{D}_{5}$ were 


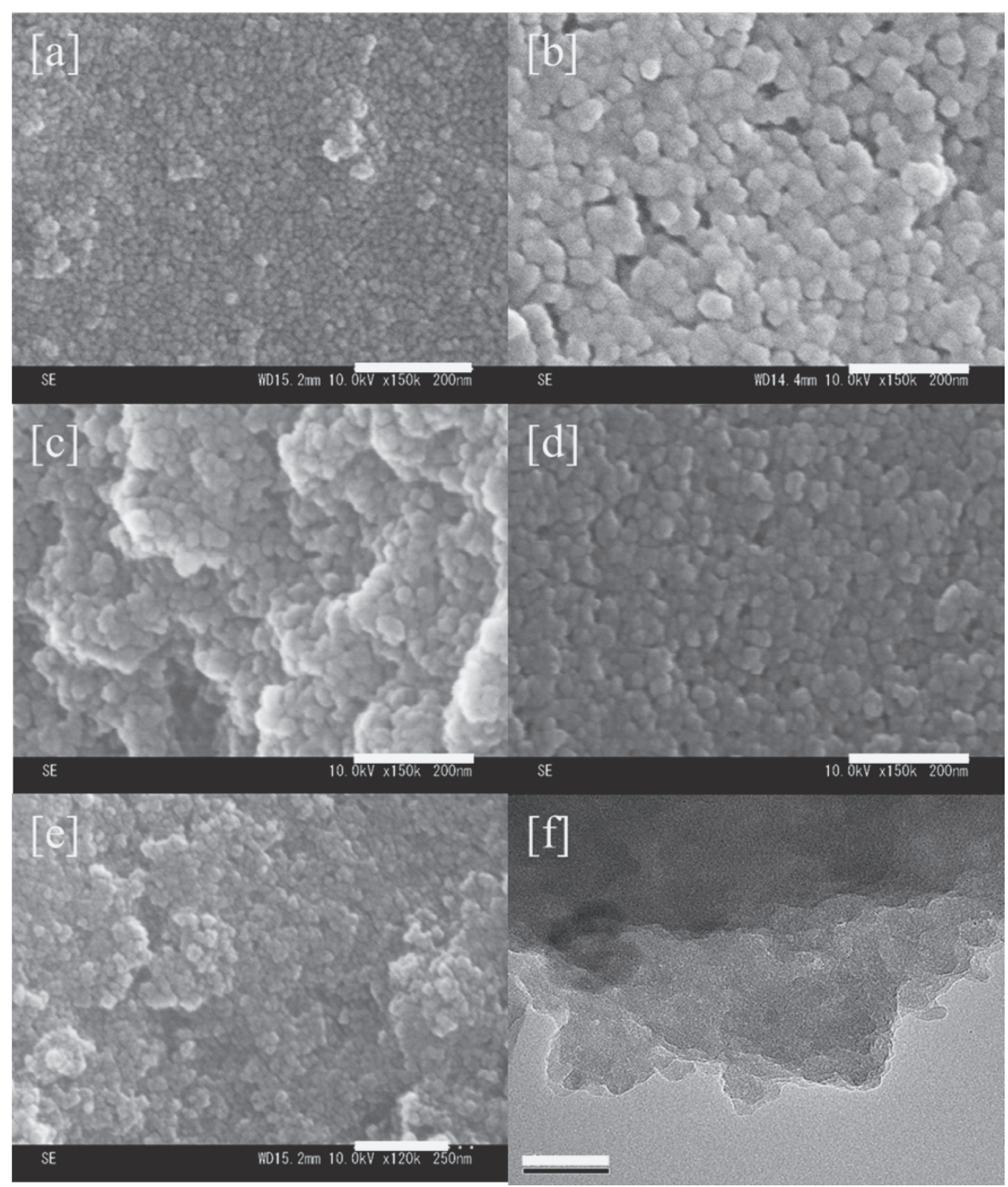

Fig. 2. FE-SEM images of silica gels prepared by mixing (a) $\mathrm{K}_{10}$ and the "leave to stand" method using (b) $\mathrm{K}_{10}$, (c) $\mathrm{H}_{10}$, (d) $(\mathrm{KD})_{5}$, and (e) $\mathrm{K}_{5} \mathrm{D}_{5}$. Scale bar: $200 \mathrm{~nm}$ (f) TEM image of silica gel prepared by "leave to stand" method using $\mathrm{K}_{10}$ as catalyst. Scale bar: $50 \mathrm{~nm}$.

approximately 25 and $15 \mathrm{~nm}$, respectively. These decreased diameters can be attributed to faster reaction rates due to a charge relay effect. ${ }^{20)}$ Figure 2(f) shows a TEM image of silica gel prepared using $\mathrm{K}_{10}$. The pore structure of this material was not uniform like that of mesoporous silica.

\subsection{The effects of synthesis conditions on silica gel pore structure}

To verify that pore size expanded with increasing silica particle diameter for silica gels prepared under different reaction conditions, the surface area and pore diameter for the particles was measured using the BET method, and the structural properties of each silica gel are summarized in Table 2. Between gels prepared using the "leave to stand" and mixing synthesis methods, there was no difference in surface area, whereas the pore volume was approximately 9 times greater in gels prepared by the "leave to stand" method. For gels prepared by mixing, the nitrogen adsorption-desorption isotherm were type-I (IUPAC), indicating the presence of micropores (Fig. 3). Also, the pore-size distribution curves displayed very few pores in the mesopore region. By contrast, the nitrogen adsorption-desorption isotherms of gels
Table 2. Nitrogen adsorption-desorption for silica gels prepared using each catalyst

\begin{tabular}{cccc}
\hline Catalyst & $\begin{array}{c}\text { Surface area } \\
\left(\mathrm{m}^{2} / \mathrm{g}\right)\end{array}$ & $\begin{array}{c}\text { Pore volume } \\
\left(\mathrm{cm}^{3} / \mathrm{g}\right)\end{array}$ & $\begin{array}{c}\text { Pore diameter } \\
(\mathrm{nm})^{\mathrm{c}}\end{array}$ \\
\hline $\mathrm{K}_{10}{ }^{\mathrm{a}}$ & 576 & 0.35 & $2-7$ \\
$\mathrm{H}_{10}{ }^{\mathrm{a}}$ & 451 & 0.30 & $2-9$ \\
$(\mathrm{KD})_{5}{ }^{\mathrm{a}}$ & 352 & 0.07 & $2-4$ \\
$\mathrm{~K}_{5} \mathrm{D}_{5}{ }^{\mathrm{a}}$ & 286 & 0.15 & $\sim 2.5$ \\
$\mathrm{~K}_{10}{ }^{\mathrm{b}}$ & 529 & 0.04 & $\sim 3.5$ \\
\hline
\end{tabular}

a: leave to stand, b: mix c: Based on BJH analysis.

prepared by the "leave to stand" method were type-IV isotherms, indicating the presence of a mesoporous structure. ${ }^{39)}$ Additionally, the pore-size distribution curves displayed that the gels prepared by the "leave to stand" method had a pore size of $2-10 \mathrm{~nm}$. Because many enzymes are $2-10 \mathrm{~nm}$ in size, these results suggest that the "leave to stand" method can be used to prepare silica gel with an appropriate pore size for use as an enzyme carrier.

Figures $\mathbf{4}$ and $\mathbf{5}$ show the nitrogen adsorption-desorption isotherm and the different pore diameter distributions resulting 


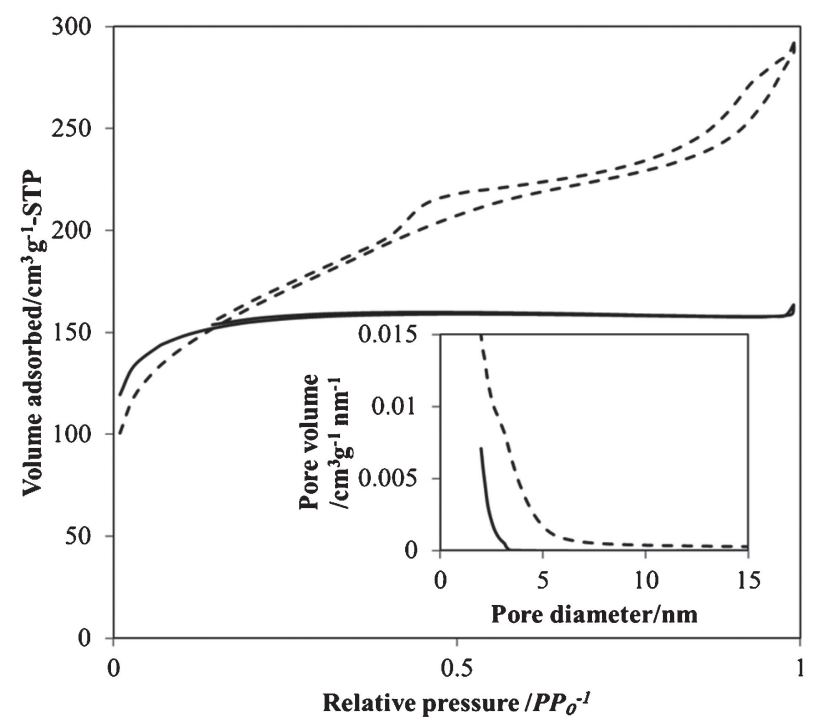

Fig. 3. Nitrogen adsorption-desorption isotherms of silica gel prepared using $\mathrm{K}_{10}$. Inset: Corresponding pore diameter distributions obtained from adsorption isotherms using the BJH method. Results for silica gels prepared by "leave to stand" method and mixing are represented by dashed line and solid line, respectively.

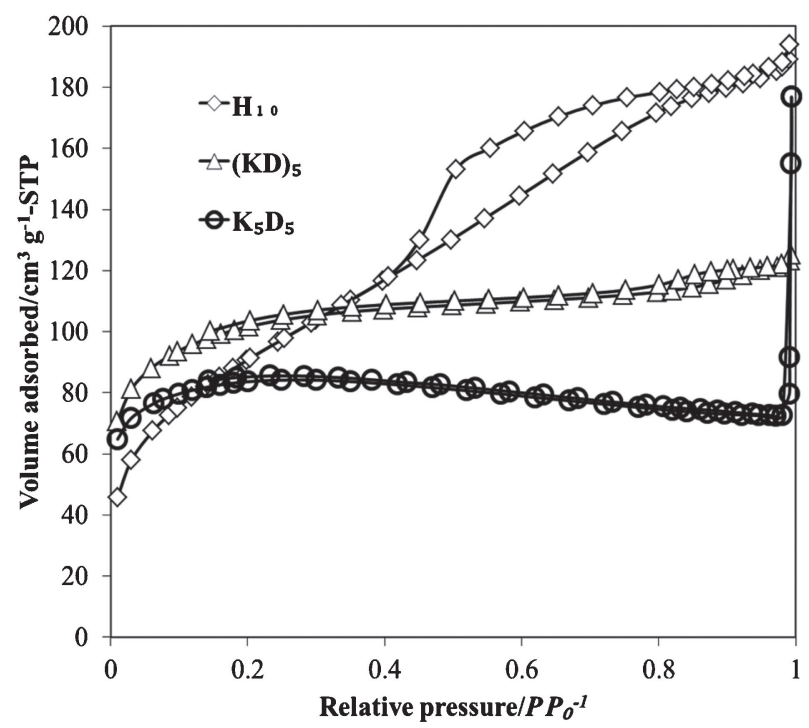

Fig. 4. Nitrogen adsorption-desorption for isotherms of silica gels prepared using $\mathrm{H}_{10}$ [squares], $(\mathrm{KD})_{5}$ [triangles], and $\mathrm{K}_{5} \mathrm{D}_{5}$ [circles].

from the use of different catalysts $\left[\mathrm{H}_{10}, \mathrm{~K}_{5} \mathrm{D}_{5}\right.$, and $\left.(\mathrm{KD})_{5}\right]$, respectively. Silica gel prepared with $\mathrm{H}_{10}$ exhibited type-IV isotherms, indicating the presence of a mesoporous structure, whereas those prepared with $(\mathrm{KD})_{5}$ and $\mathrm{K}_{5} \mathrm{D}_{5}$ showed nearly typeI isotherms (Fig. 4). Also, the pore-size distribution curve indicated that silica gel prepared with $\mathrm{H}_{10}$ had a similar pore structure to that with $\mathrm{K}_{10}$ (Fig. 5); i.e., these gels have a suitable pore structure for use as enzyme carriers. Meanwhile, silica gels prepared with $(\mathrm{KD})_{5}$ and $\mathrm{K}_{5} \mathrm{D}_{5}$ had few pores in the mesopore region, corresponding to the sizes of the respective silica particles.

Pore diameter is an important factor in determining the release rate of a drug. ${ }^{40)}$ Therefore, the effect of the functional group combined with the designed peptide sequence enables the control of the pore size, making it possible to vary the drug release rate. In summary, silica gel prepared with $\mathrm{H}_{10}$ have a pore structure

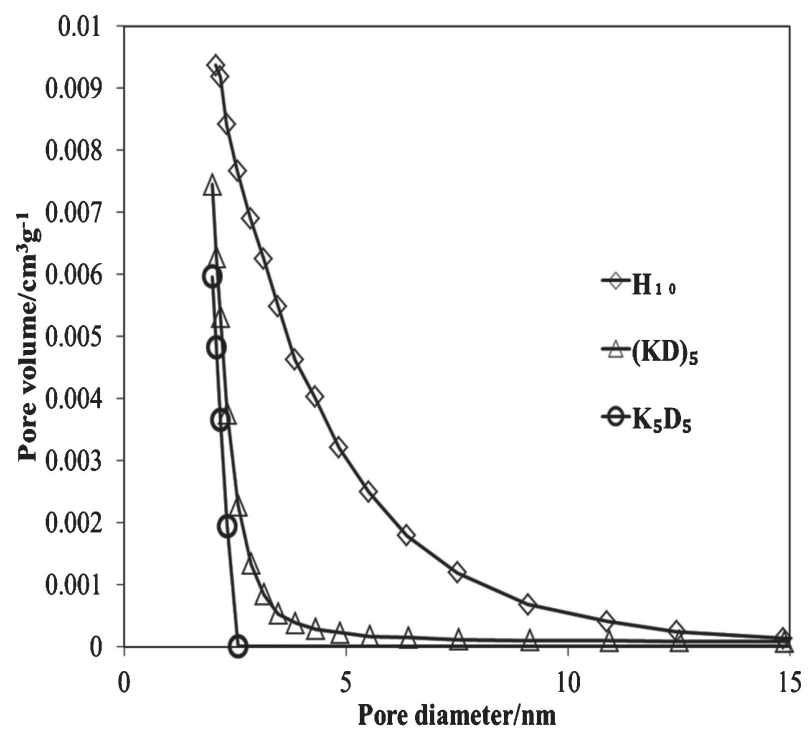

Fig. 5. Pore diameter distributions obtained from adsorption isotherms using the $\mathrm{BJH}$ method for silica gels prepared using $\mathrm{H}_{10}$ [squares], (KD) $)_{5}$ [triangles], and $\mathrm{K}_{5} \mathrm{D}_{5}$ [circles].

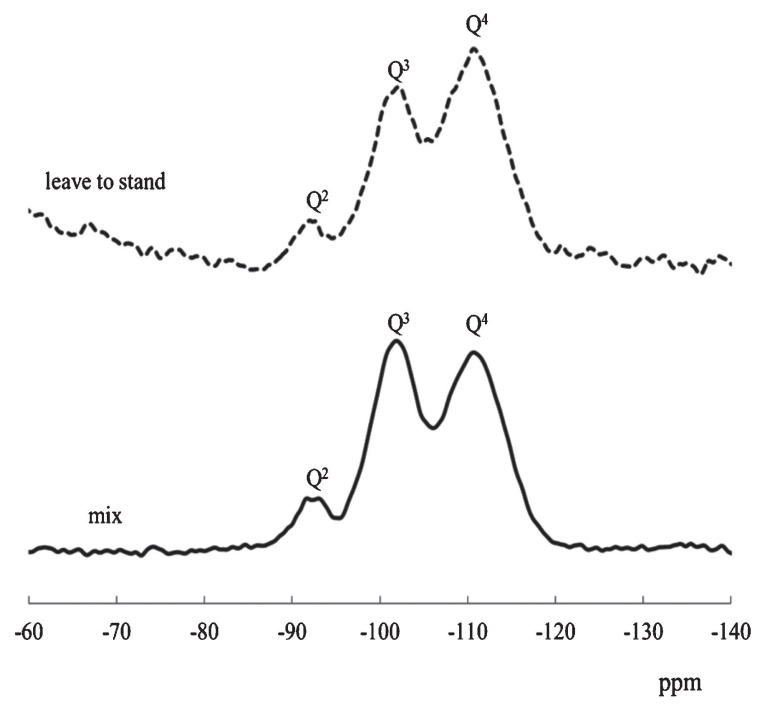

Fig. 6. ${ }^{29} \mathrm{Si}$ MAS NMR spectra of silica gels prepared by the "leave to stand" method and mixing (dashed line and solid line, respectively).

suitable for application as an enzyme carrier, and gels prepared with $(\mathrm{KD})_{5}$ and $\mathrm{K}_{5} \mathrm{D}_{5}$ have few pores in the mesopore region due to differences in silica sphere size.

\subsection{The effects of synthesis conditions on silica gel chemical properties}

Figure 6 and Table 3 show solid state ${ }^{29} \mathrm{Si} \mathrm{NMR} \mathrm{spectrum}$ of silica particles made using $\mathrm{K}_{10}$. $\mathrm{Q}^{\mathrm{n}}$ species are silicon atoms in the silica network that are connected to other silicon atoms through a bridging oxygen bond (oxygen atoms covalently bound to two silicon atoms, $\mathrm{Si}-\mathrm{O}-\mathrm{Si}$ ). Three signals could be distinguished with typical shifts of $-91,-100$, and $-108 \mathrm{ppm}$, which correspond to different silicon species $\mathrm{Q}^{2}, \mathrm{Q}^{3}$, and $\mathrm{Q}^{4}$, respectively. Connectivity was calculated according to the equation: connectivity $=4 \times \mathrm{Q}^{4} \%+3 \times \mathrm{Q}^{3} \%+2 \times \mathrm{Q}^{2} \%$. The $\mathrm{Q}^{4}$ species concentration in silica gel prepared by the "leave to stand" method $(62 \%)$ was higher than that in gel prepared by mixing 
Table 3. ${ }^{29} \mathrm{Si}$ MAS NMR data for measured samples, giving the spectral deconvolution in different $\mathrm{Q}^{\mathrm{n}}$ species. $\delta$ and $I$ represent the ${ }^{29} \mathrm{Si}$ chemical shift and relative intensity, respectively

\begin{tabular}{lcclccccc}
\hline & \multicolumn{2}{c}{$\mathrm{Q} 2$} & & \multicolumn{2}{c}{$\mathrm{Q} 3$} & & \multicolumn{2}{c}{$\mathrm{Q} 4$} \\
\cline { 2 - 3 } \cline { 8 - 9 } \cline { 8 - 9 } & $\delta / \mathrm{ppm}$ & $I(\%)$ & & $\delta / \mathrm{ppm}$ & $I(\%)$ & & $\delta / \mathrm{ppm}$ & $I(\%)$ \\
\hline leave to stand & -92.1 & 5 & & -101.5 & 33 & & -110.6 & 62 \\
mixing & -92.3 & 9 & & -101.3 & 40 & & -110.7 & 51 \\
\hline
\end{tabular}

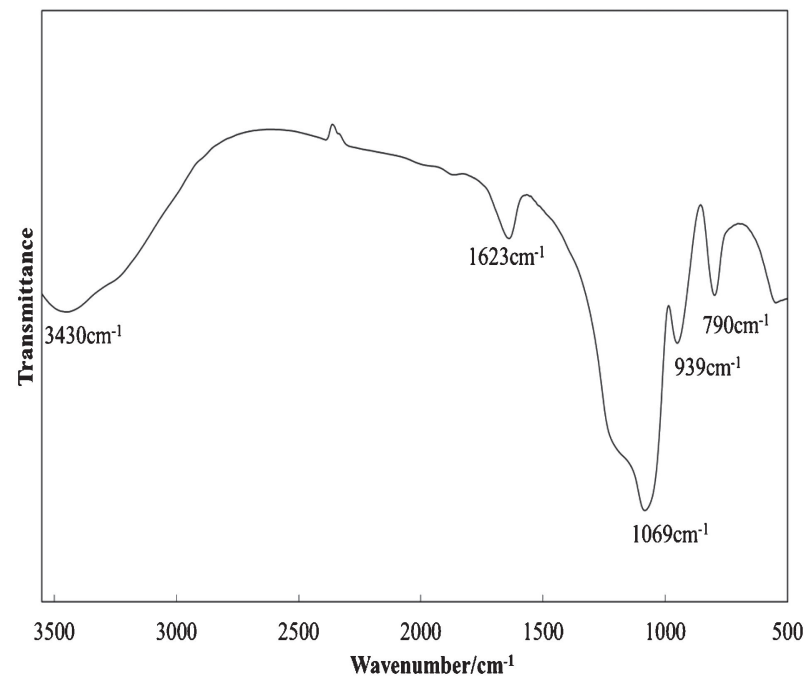

Fig. 7. FT-IR spectrum of silica particles synthesized by catalysis with $\mathrm{K}_{10}$.

(51\%). Moreover, silica network connectivity of gel prepared by the "leave to stand" method (3.57) was higher than that of gel prepared by mixing (3.42). These results indicate that silica gel prepared by the "leave to stand" method had sufficient silica network connectivity.

Figure 7 shows the FT-IR spectrum of silica particles made using $\mathrm{K}_{10}$. Near $790 \mathrm{~cm}^{-1}$, a weak band due to Si-O-Si symmetric stretching was observed. The sharp absorption band observed at $1069 \mathrm{~cm}^{-1}$ is ascribed to $\mathrm{Si}-\mathrm{O}-\mathrm{Si}$ antisymmetric stretching. The band centered at $939 \mathrm{~cm}^{-1}$ is attributed to $\mathrm{Si}-\mathrm{OH}$ stretching vibrations. The broad bands at 3430 and $1623 \mathrm{~cm}^{-1}$ can be attributed to adsorbed water or intra- and hydrogen bonds of the silanol groups. Figure 8 shows the results of TG-DTA analysis, obtained for the silica particles made with $\mathrm{K}_{10}$. The first step between room temperature and $150^{\circ} \mathrm{C}$ is approximately $10 \mathrm{wt} \%$ of the total weight loss and an endothermic peak, which can be attributed to physically adsorbed water. The second step in the range $200-350^{\circ} \mathrm{C}$ appears to be an exothermic peak and represents a weight loss of approximately $2 \mathrm{wt} \%$, which can be attributed to the decomposition of $\mathrm{K}_{10}$. The last step in the range $350-1000^{\circ} \mathrm{C}$ appears to represent a continuous weight loss with the increase in temperature and only accounts for approximately $5 \mathrm{wt} \%$ of the weight loss and is caused by the elimination of residual hydroxyl groups. These results indicate the the prepared gels were a silica-peptide composite.

\subsection{The effects of synthesis conditions on drug release behavior from silica gel}

Figure 9(a) shows FSS encapsulated within the silica hydrogel. Figure 9(b) illustrates the chemical formula of FSS, and Fig. 9 shows the release profiles of FSS from silica hydrogel made using $\mathrm{K}$ and $\mathrm{H}$. These profiles clearly demonstrated that

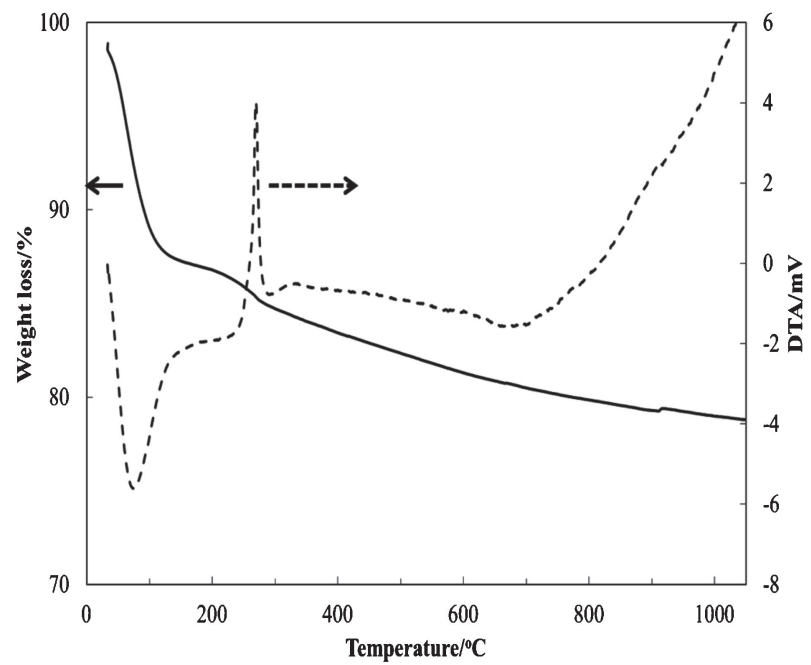

Fig. 8. TG-DTA curve of silica particles synthesized by catalysis with $\mathrm{K}_{10}$. TG curve and DTA curve are denoted by solid line and dashed line, respectively.

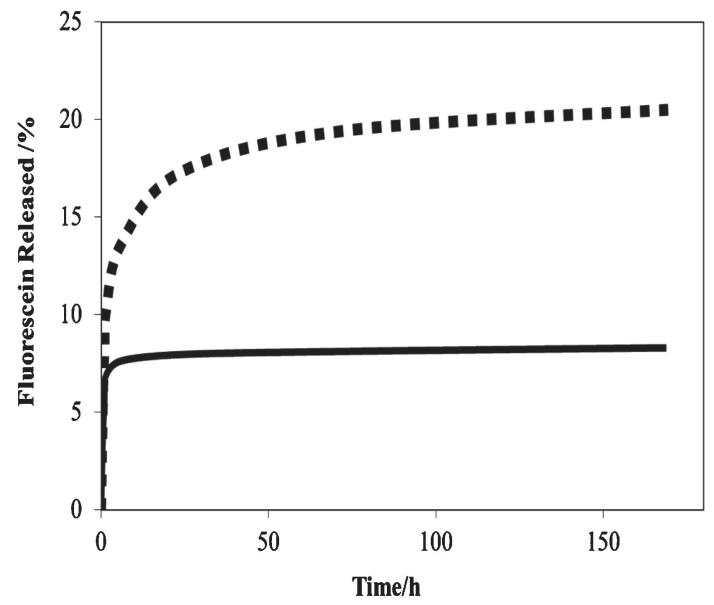

Fig. 9. Release profile of fluorescein from silica gels prepared using $\mathrm{K}_{10}$ and $\mathrm{H}_{10}$ (solid line and dashed line, respectively).

the drug was released much faster (approximately 2.5-fold) from the silica hydrogel prepared using $\mathrm{H}_{10}$ than from that prepared using $\mathrm{K}_{10}$. This can be explained by the ability of the $\mathrm{K}$ residue to absorb FSS more strongly than the $\mathrm{H}$ residue can due to the charge-charge interaction between the negatively charged FSS and the more strongly positively charged $\mathrm{K}$.

\section{Conclusions}

To design a suitable carrier for encapsulating drugs and proteins (enzymes), silica gel was prepared using synthetic peptide catalysts under mild conditions (ambient temperature, normal pressure, and a natural $\mathrm{pH}$ ) by a "leave to stand" method. All silica hydrogels prepared by this method had a silica content of less than $10 \%$. In addition, for gel preparation by this method, the amount of released ethanol was lower, and thus, this synthesis method will have a less harmful effect on the drugs and enzymes to be encapsulated. The prepared silica hydrogels were lyophilized, and their structures were examined using the BET method. Silica gels prepared by the "leave to stand" method along with $\mathrm{K}_{10}$ or $\mathrm{H}_{10}$ exhibited a mesoporous structure with a high surface area (576 and $451 \mathrm{~m}^{2} \mathrm{~g}^{-1}$, respectively) and pore volume $(0.35$ and $0.30 \mathrm{~cm}^{3} \mathrm{~g}^{-1}$, respectively). By contrast, silica gel prepared 
by mixing along with $\mathrm{K}_{10}$ did not have a mesoporous structure. These results were confirmed by SEM. Moreover, the encapsulation of FSS as a model drug during gel synthesis was demonstrated. The silica hydrogel prepared using $\mathrm{H}_{10}$ released FSS more quickly (approximately 2.5 -fold) than that prepared using $\mathrm{K}_{10}$, and this can be explained by the greater affinity of K for FSS due to the charge-charge interaction between negatively charged FSS and more strongly positively charged K. These results demonstrate that the rate of drug release from silica gel prepared by the "leave to stand" method can be varied by changing the charge intensity or the peptide sequence of the catalyst, and use to drug release carrier. In conclusion, we successfully synthesized silica gel with a mesoporous structure without using an organic template or harsh conditions. The resultant gels are an attractive option for the encapsulation of various biomolecules.

\section{References}

1) P. L. Edmiston, C. L. Wambolt, M. K. Smith and S. S. Saavedra, J. Colloid Interface Sci., 163, 395-406 (1994).

2) J. Lin and C. W. Brown, Trends Analyt. Chem., 16, 200-211 (1997).

3) K. Kato, M. Nishida, K. Ito and M. Tomita, Appl. Surf. Sci., 262, 69-75 (2012).

4) T. Pirzada, S. A. Arvidson, C. D. Saquing, S. S. Shah and S. A. Khan, Langmuir, 28, 5834-5844 (2012).

5) A. Rai, A. Prabhune and C. C. Perry, Mater. Sci. Eng., C, 32, 785-789 (2012).

6) U. Lad, G. M. Kale and R. Bryaskova, Anal. Chem., 85, 63496355 (2013).

7) D. T. Nguyen, M. Smit, B. Dunn and J. I. Zink, Chem. Mater, 14, 4300-4306 (2002)

8) H. F.-Mullerad and D. Avnir, J. Am. Chem. Soc., 127, 80778081 (2005).

9) Y. Masuda, S. Kugimiya, K. Murai, A. Hayashi and K. Kato, Colloids Surf., B, 101, 26-33 (2013).

10) P. Si, S. Ding, J. Yuan, X. W. Lou and D.-H. Kim, ACS Nano, 5, 7617-7626 (2011)

11) R. E. Luckham and J. D. Brennan, Analyst, 135, 2028-2035 (2010).

12) C. T. Kresge, M. E. Leonowicz, W. J. Roth, J. C. Vartuli and J. S. Beck, Nature, 359, 710-712 (1992).

13) S. Mann, D. D. Archibald, J. M. Didymus, T. Douglas, B. R. Heywood, F. C. Meldrum and N. J. Reeves, Science, 261, 1286-1292 (1993).

14) S. Mann, Nature, 365, 499-505 (1993).

15) X. Shen, A. M. Belcher, P. K. Hansma, G. D. Stucky and D. E. Morse, J. Biol. Chem., 272, 32472-32481 (1997).

16) S. I. Stupp and P. V. Braun, Science, 277, 1242-1248 (1997).
17) T. Nonoyama, T. Kinoshita, M. Higuchi, K. Nagata, M. Tanaka, K. Sato and K. Kato, Langmuir, 27, 7077-7083 (2011).

18) T. Nonoyama, T. Kinoshita, M. Higuchi, K. Nagata, M. Tanaka, K. Sato and K. Kato, J. Am. Chem. Soc., 134, 88418847 (2012).

19) F. Nagata, T. Miyajima and Y. Yokogawa, Chem. Lett., 32, 784-785 (2003).

20) C. Chen and N. L. Rosi, Angew. Chem., Int. Ed., 49, 1924$1942(2010)$.

21) T. Kuno, T. Nonoyama, K. Hirao and K. Kato, Langmuir, 27, 13154-13158 (2011).

22) J. M. Johnson, N. Kinsinger, C. Sun, D. Li and D. Kisailus, J. Am. Chem. Soc., 134, 13974-13977 (2012).

23) N. Kröger, Chem. Biol., 11, 662-669 (2007).

24) C. C. Perry, D. Belton and K. Shafran, Prog. Mol. Subcell. Biol., 33, 269-299 (2003).

25) N. Poulsen, M. Sumper and N. Kröger, Proc. Natl. Acad. Sci. U.S.A., 100, 12075-12080 (2003).

26) H. R. Luckarift, J. C. Spain, R. R. Naik and M. O. Stone, Nat. Biotechnol., 22, 211-213 (2004).

27) H. R. Luckarift, M. B. Dickerson, K. H. Sandhage and J. C. Spain, Small, 2, 640-643 (2006).

28) T. Shiomi, T. Tsunoda, A. Kawai, F. Mizukami and K. Sakaguchi, Chem. Mater., 29, 189-196 (2003).

29) T. Coradin, A. Coupé and J. Livage, Colloids Surf., B, 29, 189$196(2003)$

30) M. M. Tomczak, D. D. Glawe, L. F. Drummy, C. G. Lawrence, M. O. Stone, C. C. Perry, D. J. Pochan, T. J. Deming and R. R. Naik, J. Am. Chem. Soc., 127, 12577-12582 (2005).

$31)$ C. Gautier, P. J. Lopez, J. Livage and T. Coradin, J. Colloid Interface Sci., 309, 44-48 (2007).

32) K. M. Hawkins, S. S.-S. Wang, D. M. Ford and D. F. Shantz, J. Am. Chem. Soc., 126, 9112-9119 (2004).

33) S. V. Patwardhan, R. Maheshwari, N. Mukherjee, K. L. Kiick and S. J. Clarson, Biomacromolecules, 7, 491-497 (2006).

34) L. Xia and Z. Li, Langmuir, 27, 1116-1122 (2011).

35) S. Kessel, A. Thomas and H. G. Boerner, Angew. Chem., Int. Ed., 46, 9023-9026 (2007).

36) K. M. Hawkins, S. S. S. Wang, D. M. Ford and D. F. Shantz, J. Am. Chem. Soc., 126, 9112-9119 (2004).

37) J.-S. Jan, P.-J. Chen and Y.-H. Ho, J. Colloid Interface Sci., 358, 409-415 (2011).

38) J.-S. Jan, T.-H. Chuang, P.-J. Chen and H. Teng, Langmuir, 27, 2834-2843 (2011)

39) M. Kruk and M. Jaroniec, Chem. Mater., 13, 3169-3183 (2001).

40) Z. Guo, X.-M. Liu, L. Maa, J. Li, H. Zhang, Y.-P. Gao and Y. Yuan, Colloids Surf., B, 101, 228-235 (2013). 